\author{
Marijana PALALIC ${ }^{1 *}$, Hans-Christian MÖHRING ${ }^{1}$, \\ Walther MAIER ${ }^{1}$, Adrian Gonzalez de MENDOZA ${ }^{2}$, \\ Friedrich RIEMEIER ${ }^{2}$
}

\title{
MULTIAXIAL FORCE PLATFORM WITH DISTURBANCE COMPENSATION FOR MACHINE TOOLS
}

\begin{abstract}
As part of a cooperation project between the Institute for Machine Tools, Stuttgart, Germany, and EMO Systems/Nuton GmbH, Berlin, Germany, a prototype of a multiaxial force platform with disturbance compensation for the measurement of the cutting forces in machine tools was developed. Commercially available products based on piezoelectric technology are subject to a degree of measurement uncertainty and therefore characterized by various disturbances. Interpreting measurement data of the commercially available products is complex, timeconsuming and prone to errors. This paper describes the mechanical design and the simulation of the multiaxial force measuring system with the finite element method (FEM) as well as the conceptual development of a reduced model for a multibody simulation with the purpose of implementing a compensation algorithm. The measurement uncertainty was reduced by using appropriate hardware and software for the compensation of the various disturbances so that the application of the force platform would also be possible in the industrial application for the process diagnosis, the control and the regulation in machine tools. Systems based on strain gauge technology have some advantages in the field of zero-point stability and also provide a less expensive solution. For the disturbance compensation, an additional force and torque sensor system with eight channels was used for the detection of the platform displacement and inclination. With the help of appropriate algorithms for the disturbance compensation and their integration in the evaluation software, the disturbances could be reduced to a minimum.
\end{abstract}

\section{INTRODUCTION}

Multiaxial force measuring plates with integrated disturbance compensation, as presented in this paper, can be used for monitoring and controlling the force of cutting processes, e.g. via the machine feed rate or the spindle speed. By using real-time detection of disturbances in the cutting process due to tool wear or tool failure, the machine tool control system can automatically change the cutting parameters or interrupt the process. The highresolution force measuring equipment enables scanning operations for both tool and workpiece measurement in the machine tool. It is of essential importance that the measured forces correspond to the real forces occurring between the tool and the workpiece, and that

\footnotetext{
${ }^{1}$ University of Stuttgart, Institute for Machine Tools (IfW), Stuttgart, Germany,

${ }^{2}$ EMO Systems GmbH/Nuton GmbH, Berlin, Germany

*E-mail: marijana.palalic@ifw.uni-stuttgart.de https://doi.org/10.36897/jme/127105
} 
the force signal is differentiated from the disturbance and noise signals. Measuring errors in the cutting process due to disturbances are caused by heat effects, moments of inertia of the moving parts as well as external vibrations or impulses. The demand for high component quality with ever-increasing productivity has made the application of sensors in the cutting production an integral part. Klocke et al. provided an overview of sensors used in digital production [1].

Denkena et al. [2] described an application of a self-regulating process-monitoring system for the detection of errors. Based on a multi-criteria evaluation of the sensor measurement data, the process characteristics were identified with a reference signal using the correlation analysis. An expert system chose the process standard from the reference signal. If a characteristic value exceeded a threshold, an error was detected.

The process monitoring of a milling process is also possible by means of the tool. With a "DynaTool" tool developed within the CORNET project, it is possible to detect the critical tool vibrations during the cutting operation and initiate a reduction in vibrations with the appropriate compensation strategies [3]. Another sensor tool for monitoring milling processes with force and temperature sensors as well as a MEMS acceleration and position sensor, which can detect rotational speed, vibrations and impacts, was also developed within a ZIM (Zentrales Innovationsprogramm Mittelstand - Innovation programme for small and medium-sized enterprises) cooperation project of the Institute for Machine tools at the University of Stuttgart [4], [5].

Multiaxial force platforms are state-of-the-art force measuring systems. Regarding resultant force analysis, particularly the piezoelectric systems by Kistler [6] are predominant on the market. The measuring systems by Kistler are based on numerous patents [7], [8]. In the area of resultant force measurements at the workpiece, the force measuring systems by Kistler are implemented in many research facilities and test laboratories. These systems were optimized [9] and compared to the known measuring systems [10]. They are characterized by a high stiffness, a high natural frequency, and a high sensitivity. The high sensitivity of the dynamometer is based on the piezoelectric measuring principle providing a high-resolution acquisition of the smallest mechanical loads with a high sampling rate.

Totis et al. presented in [10] a new measuring system for the application in small milling and drilling machines with very high rotational speed. The system combined three highsensitive triaxial-piezoelectric sensors in a new triangular configuration.

\section{DESIGN AND TECHNOLOGICAL BASIS}

The basis of the project development was protected by several German patent applications by the project partner EMO Systems/Nuton [11]-[16]. The applications refer to the design of the sensors, the wiring, and the temperature control. The following aspects were of particular importance for the configuration of the force platform:

1. The multi-redundant detection of all force components led to a high sensitivity and a high-resolution strain gauge measuring system.

2. An extremely short circular deformation zone of the sensor ensured a high rigidity and a high natural frequency while allowing a very low overall height of the force platform at the same time. 
3. The temperature control of the sensor allowed a high supply voltage and thus ensured an increased sensitivity. In addition, the temperature control improved the zero-point stability and drastically decreased the thermal settling time.

With regard to measurement data rate, rigidity, natural frequency, and overload capacity, the developed technology described above was comparable with the measuring systems by Kistler.

In Table 1 the essential characteristics and parameters of the force measuring systems with piezoelectric technology and strain gauge technology are summarized and compared. It can be seen that the developed measuring system usually receives a better evaluation due to a different measurement principle. In some areas, however, optimizations were carried out in the force platform based on strain gauge technology.

Table 1. Comparison of the measuring systems with piezoelectric and strain gauge technology

\begin{tabular}{|c|c|c|c|c|}
\hline $\begin{array}{l}\text { Characteristic } \\
\text { parameters }\end{array}$ & Piezoelectric technology & Evaluation & $\begin{array}{l}\text { Strain gauge } \\
\text { technology }\end{array}$ & Evaluation \\
\hline Anisotropy & $\begin{array}{l}\text { arrangement of the crystal } \\
\text { structure }\end{array}$ & complex & $\begin{array}{l}\text { arrangement of the } \\
\text { strain gauges }\end{array}$ & simple \\
\hline Measuring system & $\begin{array}{l}\text { dynamometer-charge } \\
\text { amplifier-voltmeter }\end{array}$ & $\begin{array}{l}\text { long, } \\
\text { complex }\end{array}$ & strain gauge amplifier & short, middle \\
\hline $\begin{array}{c}\text { Long-term } \\
\text { measurement }\end{array}$ & $\begin{array}{c}\text { only "quasi-static" and } \\
\text { dynamic }\end{array}$ & - & static and dynamic & + \\
\hline Zero drift & $\begin{array}{l}\text { high, many influence factors } \\
\text { (charge difference, insulation } \\
\text { resistance, air humidity, } \\
\text { contact resistance); also } \\
\text { temperature } \\
\end{array}$ & - & $\begin{array}{l}\text { middle, temperature, } \\
\text { mechanical tension }\end{array}$ & o \\
\hline Stiffness & high & + & $\begin{array}{l}\text { design-dependent, high } \\
\text { stiffness achievable }\end{array}$ & $\mathrm{o} /+$ \\
\hline Natural frequency & high & + & $\begin{array}{c}\text { design-dependent, high } \\
\text { natural frequency } \\
\text { achievable } \\
\end{array}$ & $\mathrm{o} /+$ \\
\hline Temperature drift & complex & - & $\begin{array}{c}\text { can be compensated } \\
\text { and temperature } \\
\text { regulated }\end{array}$ & $\mathrm{o} /+$ \\
\hline $\begin{array}{l}\text { Measurement } \\
\text { principle }\end{array}$ & $\begin{array}{l}\text { relative, zeroing is necessary } \\
\text { before every measurement }\end{array}$ & - & $\begin{array}{c}\text { absolute, no zeroing } \\
\text { necessary }\end{array}$ & + \\
\hline Wiring & $\begin{array}{l}\text { complex, expensive charge } \\
\text { cable, sensitive to bending, } \\
\text { limited in length }\end{array}$ & - & $\begin{array}{l}\text { simple multiline power } \\
\text { cable (also suitable for } \\
\text { power chain) }\end{array}$ & + \\
\hline
\end{tabular}

The technological approach selected for the development of the measuring system also enabled an easy implementation for a high sensitivity acquisition of disturbances such as inclinations, linear and rotational accelerations, impulses and vibrations in six axes with the same sensitivity and measurement rate as the force plate itself.

Being used here was a disturbance sensor which was designed as a six-axis force measuring system and was technologically very similar to the force plate sensors. The disturbance sensor was based on the concept for a six-axis measuring ring, protected by 
property rights [13]. This measuring ring was coupled with a substitute mass, which was positioned independently from the measuring table of the platform and could measure all accelerations, inclinations, and vibrations acting on the base of the force plate as well as external disturbances. The basic structure of the described system and a procedure for disturbance compensation was specified in another patent application [14]. A basic principle of the presented measuring system is described in Fig. 1.

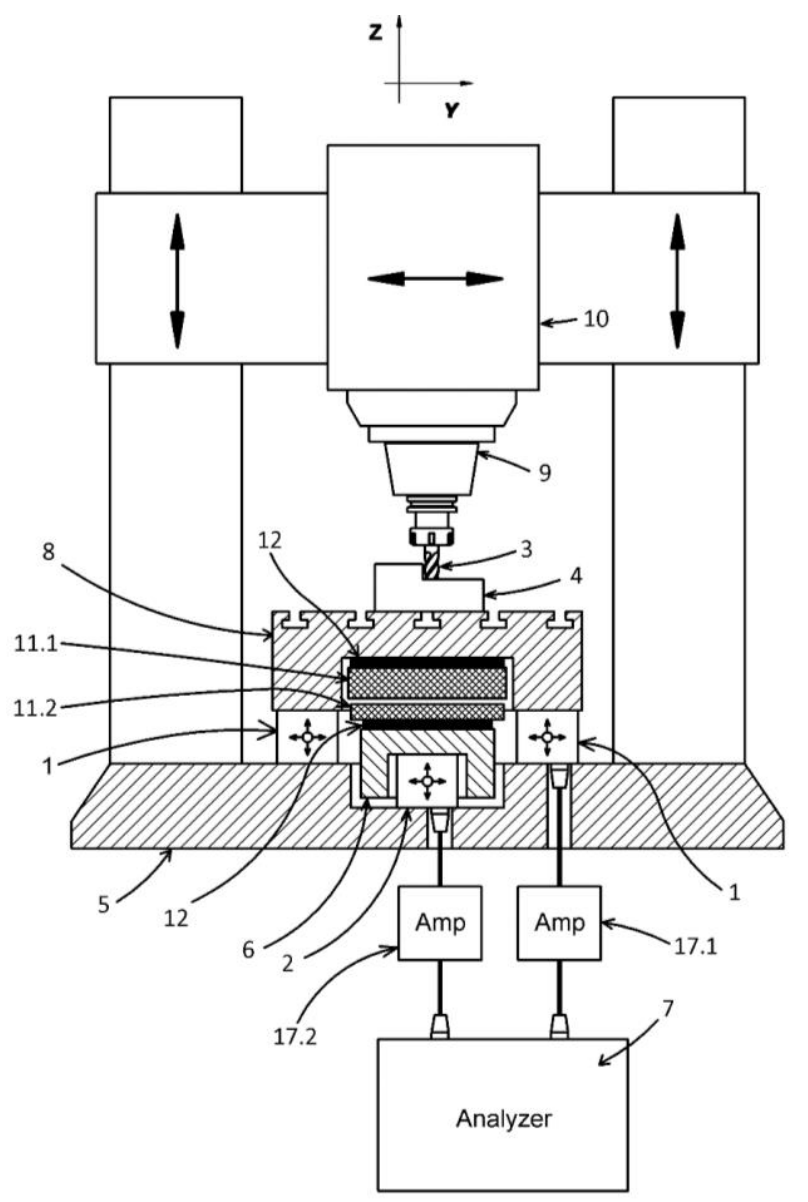

Fig. 1 Diagram of the force measuring system with disturbance sensor in a machine tool [16]

Therefore, the technology of a disturbance sensor shown here (2) represented a possibility to measure relevant disturbances and also provided an important approach to disturbance compensation. This technology was of considerable relevance since it was adaptable with regard to sensitivity, resolution, measurement data rate, zero-point stability, and natural frequency of the force plate and moreover could be synchronized in a simple way. Generally, disturbance compensation is also used in other technical fields, e.g. in acoustics. However, the known disturbance compensation solutions, especially adapted to the particular requirements of process analysis in machine tools, provide only very limited information, such as vibration measurement data of the machine body, which are analysed separately. The necessary compensation for the wide range of complex disturbance sources with a high market acceptance is completely missing in the previously developed systems. 


\section{MODELLING OF THE MECHANICAL SYSTEM}

Force measurement is influenced by various disturbances as well as operation and measurement noise. Within the scope of the ZIM project, the model-based compensation techniques were used to attain the best information about the real forces occurring in the cutting process. As an essential part of the compensation algorithm development, an appropriate mathematical model developed for the force measuring system is presented in this paper.

The mechanical system was initially analysed by using finite element modelling software. The finite element method is a numerical method used for the determination of the displacement response of the mechanical force measuring system by discretizing the system into finite elements in order to numerically approximate the mathematical equations that define its behaviour. By means of FEM, the system is discretized into mesh consisting of nodes and elements. The general form of the equation of motion for structural analysis is described by:

$$
[M]\{\ddot{u}\}+[C]\{\dot{u}\}+[K]\{u\}=\{F\}
$$

where $\{\mathrm{u}\}$ are the nodal degrees of freedom, $[M]$ is the mass matrix, $[C]$ is the damping matrix, $[K]$ is the stiffness matrix, and $\{F\}$ is the load vector.

The discretization of the system introduces matrices of a large order to the mathematical model. In order to implement the compensation algorithms, the model obtained from the FEsoftware is reduced to a smaller degrees-of-freedom model while maintaining the essential dynamic characteristics of the original mechanical system.

The reduced model was implemented in a Matlab/Simscape Multibody environment using Flexible Body Library [17]. The method used in this paper for the modelling of a flexible body was the finite element import method, as suggested in [18].

The well-known reduction method employed in this paper is the substructure method, presented by Craig and Bampton in 1968 [19]. Another level added to the hierarchy of the problem domain is the substructure. The basic idea behind the substructuring analysis is to divide the system into substructures to be reduced into degrees of freedom and their coupling to the whole system. Substructuring also provides a possibility for an independent analysis of the individual components, i.e. substructures [20].

In the Craig-Bampton reduction method [19], the substructure is divided into interior degrees of freedom and boundary degrees of freedom. The displacements of the substructure are described by "constraint modes" and "normal modes".

The static system representation is partitioned to boundary or master and internal or slave groups as follows:

$$
\left[\begin{array}{cc}
K_{b b} & K_{b i} \\
K_{i b} & K_{i i}
\end{array}\right]\left\{\begin{array}{l}
u_{b} \\
u_{i}
\end{array}\right\}=\left\{\begin{array}{l}
F_{b} \\
F_{i}
\end{array}\right\}
$$

where $b$ is the subscript for boundary and $i$ the subscript for internal. 
In the Craig-Bampton approach [19], constraint modes are defined as the mode shapes obtained due to the successive unit displacement of boundary points while all other boundary points are constrained, which yields the matrix of static constraint modes:

$$
\left\{u_{i}\right\}=\left[\Phi_{c}\right]\left\{u_{b}\right\}
$$

where $\left[\Phi_{c}\right]$ is the matrix of static constraint modes.

Consistent mass matrix formulation is used:

$$
[M]=\left[\begin{array}{ll}
M_{b b} & M_{b i} \\
M_{i b} & M_{i i}
\end{array}\right]
$$

Normal modes describe the motion of the interior freedoms relative to the fixed boundaries when all boundaries are fixed, and they are obtained from the following equation of transients [19]:

$$
\omega^{2}\left[M_{i i}\right]\left\{\Phi_{i}\right\}=\left[K_{i i}\right]\left\{\Phi_{i}\right\}
$$

where $\left\{\Phi_{i}\right\}$ are the eigenvectors which form the normal modes matrix [ $\left.\Phi_{N}\right]$.

The normal modes are truncated at the particular cut-off frequency with the assumption that the interior freedoms can be approximated by a significantly smaller set of coordinates [19]. From the assumption, a transformation matrix between the physical coordinates of boundary and internal degrees of freedom, and a hybrid set of physical coordinates of boundary degrees of freedom and truncated modal coordinates is described by:

$$
\begin{gathered}
{[T]=\left[\begin{array}{cc}
I & 0 \\
\Phi_{c} & \Phi_{N}
\end{array}\right]} \\
\{u\}=\left\{\begin{array}{l}
u_{b} \\
u_{i}
\end{array}\right\}=[T]\left\{\begin{array}{l}
u_{b} \\
p_{i}
\end{array}\right\}
\end{gathered}
$$

where $[I]$ is the identity matrix and $\left\{p_{i}\right\}$ are the amplitudes of the modal vectors from the normal modes matrix, $[T]$ is the transformation matrix.

For the Craig-Bampton reduction method [19], the final reduced system matrices have the following form:

$$
\begin{gathered}
{[\bar{K}]=[T]^{T}[K][T]=\left[\begin{array}{cc}
\bar{K}_{b b} & 0 \\
0 & \bar{K}_{i i}
\end{array}\right]} \\
{[\bar{M}]=[T]^{T}[M][T]=\left[\begin{array}{cc}
\bar{M}_{b b} & \bar{M}_{b i} \\
\bar{M}_{i b} & I
\end{array}\right]} \\
{[\bar{C}]=[T]^{T}[C][T]=\left[\begin{array}{ll}
\bar{C}_{b b} & \bar{C}_{b i} \\
\bar{C}_{i b} & \bar{C}_{l l}
\end{array}\right]}
\end{gathered}
$$

Each sensor of the force platform was a cylindrical complex structure, varying in thickness and diameter. Sensors and cover plate, i.e. flexible bodies of the structure, were reduced using the Craig-Bampton reduction method and implemented in a Simscape Multibody environment, Fig. 2. Boundary nodes were selected in the points where the 
substructure connected to another substructure, where the loads or constraints had to be applied and where the measurement of displacement, velocity or acceleration was required.

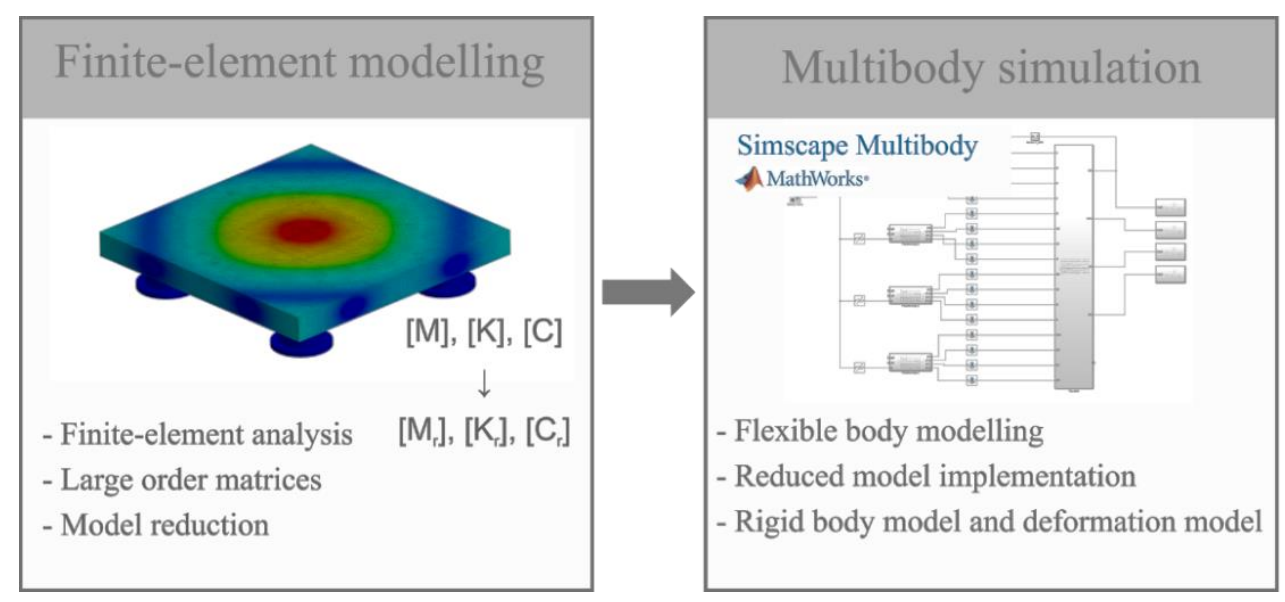

Fig. 2. Flexible body simulation environment

Simscape Multibody is a multibody simulation environment for mechanical systems that enables the control system implementation and development in Simulink. In order to model a flexible body in Simscape Multibody environment, the finite element import method was used, as suggested in [18]. The structure was implemented as the superposition of a rigidbody model and a deformation model using the Flexible Body Library [17]. The system was modelled using bodies, joints, constraints, force element and sensors. The coordinate frames that corresponded to the boundary nodes were called interface frames.

The rigid-body model was implemented as a solid body and imported using CAD data. The inertia of the flexible body was proportionally distributed to interface frames.

The deformation model imported from the finite element modelling software described the elastic deformations of the flexible structure. This deformation part was represented with a state-space model:

$$
\begin{aligned}
& \{\dot{x}\}=[A]\{x\}+[B]\{u\} \\
& \{y\}=[C]\{x\}+[D]\{u\}
\end{aligned}
$$

where (8) is the state equation described by state matrix $[A]$, input matrix $[B],[u]$ is the set of input variables (deflections of the boundary nodes), $[x]$ is the set of state variables (the amplitudes of the truncated vibration modes), and (9) is the output equation described by feedthrough matrix $[C]$, output matrix $[D]$ and $[y]$ is the set of output variables (counter forces and torques to the applied loads) [18].

The state-space matrices were calculated from the reduced mass and stiffness matrices imported from the finite element modelling software using the Craig-Bampton reduction method. In order to remove the rigid body modes, i.e. translations and rotations from the reduced model, one boundary node was fixed to the rigid body model. This frame with all its degrees of freedom set to zero was called the reference frame. 
The damping of the flexible body was approximated with the modal damping model in which the damping matrix was diagonalized and characterized by a modal damping factor $\zeta$. Finally, the state-space matrices that describe the deformation model of a flexible body represented in (8) and (9) were calculated from the reduced system mass, stiffness, and damping matrices as follows [18]:

$$
\begin{aligned}
& {[A]=\left[\begin{array}{cc}
\mathbf{0} & \mathbf{I} \\
-\bar{M}_{b b} \bar{K}_{b b} & -\bar{M}_{b b} \bar{L}_{b b}
\end{array}\right]} \\
& {[B]=\left[\begin{array}{ccc}
\mathbf{0} & \mathbf{0} & \mathbf{0} \\
-\bar{M}_{i i} \bar{K}_{i b} & -\bar{M}_{i i} \bar{K}_{i b} & -\bar{M}_{b b} \bar{M}_{i b}
\end{array}\right]} \\
& {[C]=\left[-\left(\bar{K}_{i b}-\bar{M}_{b i} \bar{M}_{i i}^{-1} \bar{K}_{i b}\right) \quad-\left(\bar{C}_{b i}-\bar{M}_{b i} \bar{M}_{i i}^{-1} \bar{L}_{i i}\right)\right]} \\
& {[D]=\left[\begin{array}{lll}
-\left(\bar{K}_{b b}-\bar{M}_{b i} \bar{M}_{i i}^{-1} \bar{K}_{i b}\right) & -\left(\bar{L}_{b b}-\bar{M}_{b i} \bar{M}_{i i}^{-1} \bar{L}_{i b}\right) & -\left(\bar{M}_{b b}-\bar{M}_{b i} \bar{M}_{i i}^{-1} \bar{M}_{i b}\right)
\end{array}\right]}
\end{aligned}
$$

\section{NUMERICAL RESULTS}

The force plate was divided into substructures and the reduced Craig-Bampton matrices were calculated using finite element modelling software. Fig. 3 shows the reduced mass and stiffness system matrices of one sensor. The original non-reduced system matrices calculated by the finite element software had more than 140,000 degrees of freedom.
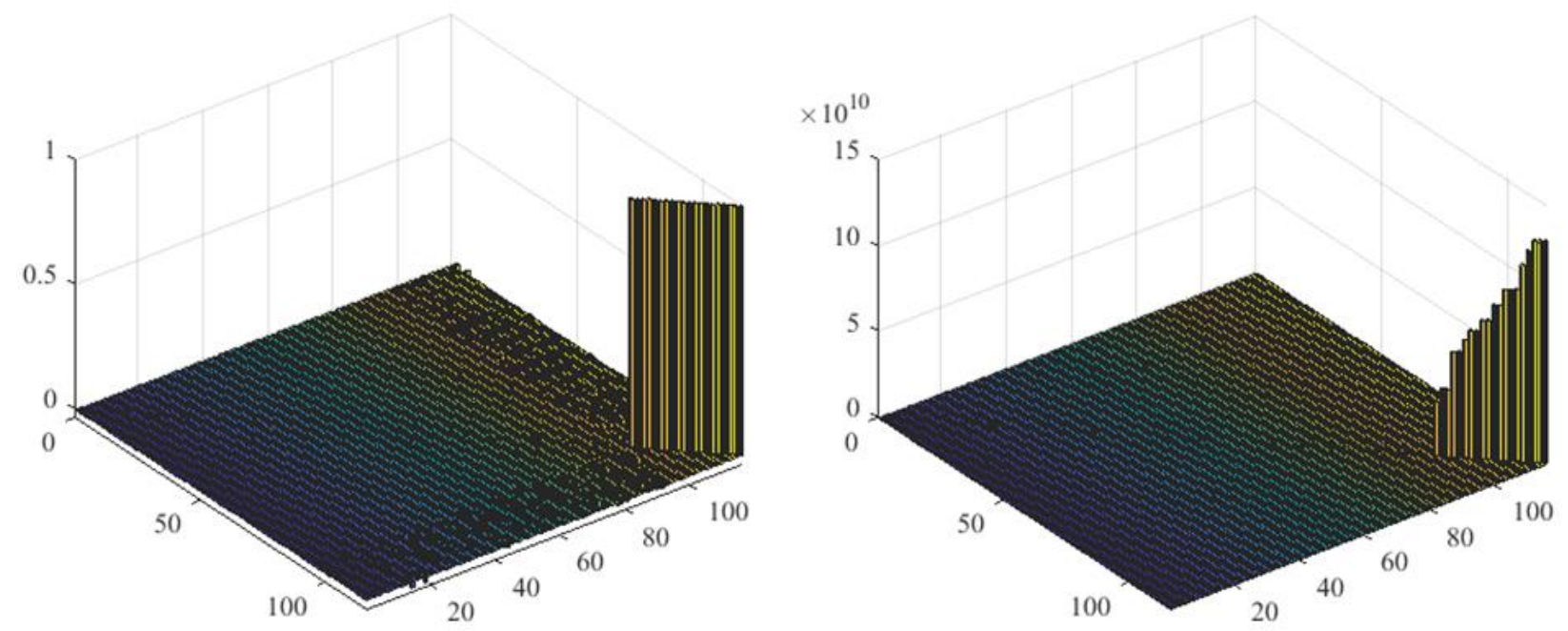

Fig. 3. Reduced system matrices (left: mass matrix, right: stiffness matrix)

The accuracy of the reduced model in the modal solution was compared to the nonreduced solution, Fig. 4 and Fig. 5.

The selected reduced model of a sensor was a model with 20 normal modes which corresponded to the non-reduced model results. The number of selected interface frames with three degrees of freedom each was $n_{b}=40$. 
The described structural model was accordingly reduced, and the state-space matrices for the deformation model were calculated as described in (8) and (9). The rigid-body model was implemented as a solid body using CAD data. The mass of the flexible body was distributed over the interface frames.

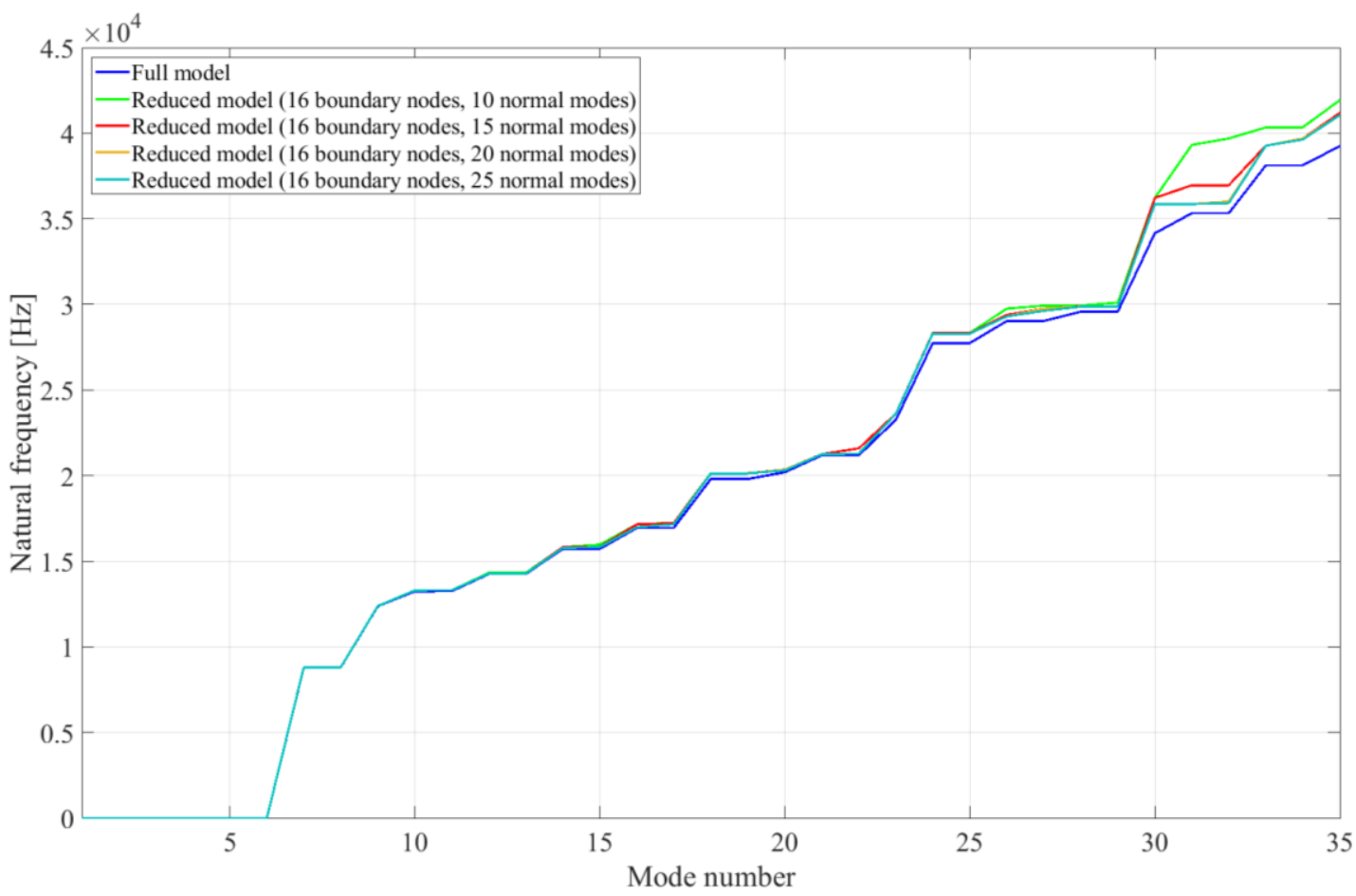

Fig. 4. Comparison of the full and reduced model

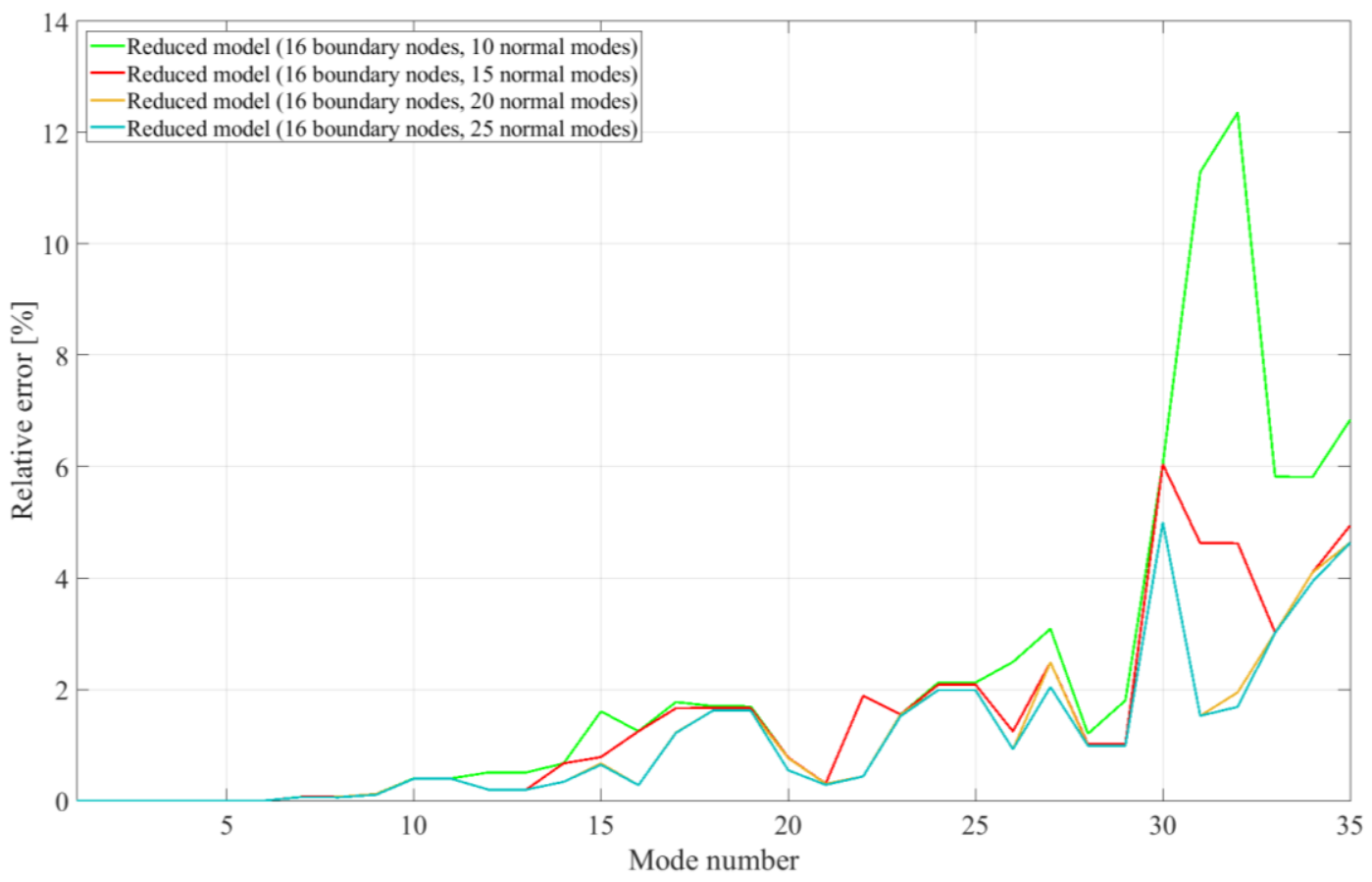

Fig. 5. Relative error diagram for different reduced models 
Figure 5 presents the deformation response in the vertical direction in the position where the strain gauge is to be applied, where $u_{\mathrm{mb}}$ is the simulation response from a multibody simulation environment Simscape Multibody and $u_{\mathrm{fem}}$ is the response from a static-structural analysis of the reduced model in a finite element software. The model of the flexible body was simulated for the two values of the modal damping factor $\zeta=1 \%$ and $\zeta=5 \%$ as presented in Fig. 6.
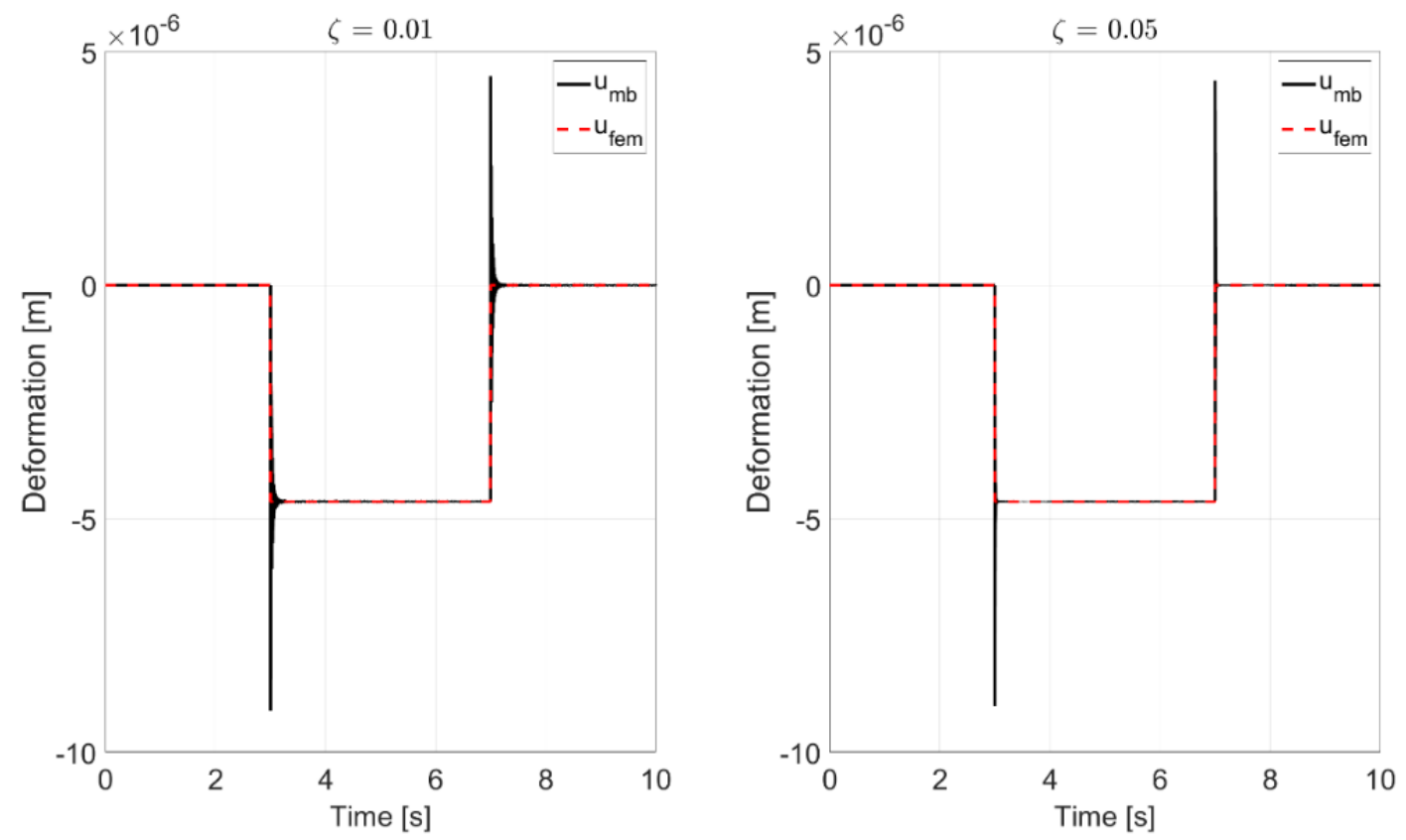

Fig. 6. Sensor - deformation response

The quality of the model depended on the selection and the number of the interface frames used to describe the reduced model of the flexible body, the cut-off frequency, the mass distribution on the interface frames, and the damping model approximation or the direct implementation from the finite element software.

\section{SUMMARY}

Force measurement in the cutting process is influenced by various disturbances that cause measuring errors, e.g. heat effects, moments of inertia of the moving parts as well as external vibrations or impulses. Hence for a precise force measurement, the measuring system must be able to differentiate the disturbances from the effective signal coming from the real force occurring between the tool and the workpiece. A force plate with integrated hardware and software for disturbance compensation was developed. As a disturbance compensation strategy, a sensor was designed on the concept for a six-axis measuring ring, coupled with a substitute mass which was adaptable with regard to sensitivity, resolution, measurement data rate, zero-point stability, and natural frequency of the force plate. 
In order to implement model-based compensation techniques, the modelling of the mechanical system using FEM-reduced solution integrated into a multibody simulation environment is presented here. With the help of a well-known Craig-Bampton reduction method, the model was reduced and implemented in a multibody simulation software to conduct further analysis and develop compensation model-based algorithms. The quality of the approximated model was influenced by the degree of model reduction, as well as the cut-off frequency, selection and number of interface frames, distribution of the mass on the interface frames and the selection of the reference body frame. In further research, the strategy for disturbance and noise compensation both acting on the process and the measurement will be developed using the described disturbance sensor and estimation algorithms.

\section{ACKNOWLEDGMENTS}

The authors thank the German Federal Ministry for Economic Affairs and Energy (BMWI) with the innovation programme for small and medium-sized enterprises (ZIM) for supporting the cooperation project.

\section{REFERENCES}

[1] KLOCKE F., JOSEPH Y., TRÄCHTLER A., et al., 2014, Sensoren für die digitale Produktion/Sensors for a digital production, Integrative Produktion - Industrie 4.0: Aachener Perspektiven, Shaker, 271-296.

[2] DENKENA B., DAHLMANN D., DAMM J., 2015, Self-Adjusting Process Monitoring System in Series Production, Innovative and Cognitive Production Technology and Systems, CIRP Conference on Intelligent Computation in Manufacturing Engineering, 9, Procedia CIRP, 33, 233-238.

[3] MÖHRING H.C., NGUYEN Q.P., KUHLMANN A., LEREN C., 2016, Intelligent Tools for Predictive Process Control, Factories of the Future in the Digital Environment, CIRP-CMS, CIRP Conference on Manufacturing Systems, 57, 539-544.

[4] MAIER W., MÖHRING H.C., WERKLE K., 2018, Tools 4.0 - Intelligence Starts on the Cutting Edge, 4th International Conference on System-Integrated Intelligence: Intelligent, Flexible and Connected Systems in Products and Production, Procedia Manufacturing, 24, 299-304.

[5] MÖHRING H.C., MAIER W., WERKLE K., 2018, Increasing the Accuracy of an Intelligent Milling Tool with Integrated Sensors, 18th International Conference \& Exhibition, $4^{\text {th }}$ to $8^{\text {th }}$ June 2018, ISBN: 978-0-9957751-2-1.

[6] https://www.kistler.com/en/products/components/force-sensors/?pfv_metrics=metric.

[7] GAUTSCHI G., KOHLER D., WOLFER P., 1993, Measuring Platform, EP000000360923B1, Europäisches Patent, Kistler Instrumente AG, 13.01.1993.

[8] SONDEREGGER H., WOLFER P., 1993, Mounting of a Force Transducer in a Measuring Platform, EP000000342253B1, Europäisches Patent, Kistler Instrumente AG, 13.01.1993.

[9] WULFSBERG J., BRUDEK G., 2004, Problemstellungen und ein Lösungsansatz zur Kraftmessung in der Mikrozerspanung, wt Werkstattstechnik online, 11/12, 625-630.

[10] TOTIS G., ADAMS O., SORTINO M., 2014, Development of an Innovative Plate Dynamometer for Advanced Milling and Drilling Applications, Measurement, 49, 164-181.

[11] GONZÁLES DE MENDOZA A.C., 2019, DE 102016116180 B4, Verfahren und Kraftmessplatte zur mehrachsigen Erfassung einwirkender Kräfte und Momente, Deutsches Patent- und Markenamt/German Patent and Trade Mark Office, Berlin, Germany.

[12] GONZÁlES DE MENDOZA A.C., 2016, DE 102016116 182.9, Deutsches Patent- und Markenamt/German Patent and Trade Mark Office, Berlin, Germany.

[13] GONZÁLES DE MENDOZA A.C., 2018, DE 102016116 182. A1, Temperaturmanagement für eine Kraftmesseinrichtung, Deutsches Patent- und Markenamt/German Patent and Trade Mark Office, Berlin, Germany. 
[14] GONZÁLES DE MENDOZA A.C., 2018, DE 102016116181 A1, Ein- oder mehrachsige Kraftmesseinrichtung mit kurzer Verformungszone, Deutsches Patent- und Markenamt/German Patent and Trade Mark Office, Berlin, Germany.

[15] GONZÁLES DE MENDOZA A.C., 2019, DE 102016114 193.B4, Kraftmesseinrichtung zur mehrachsigen Erfassung einwirkender Kräfte und Momente, Deutsches Patent- und Markenamt/German Patent and Trade Mark Office, Berlin, Germany.

[16] GONZÁLES DE MENDOZA A.C., 2019, DE 102017116 448.A1, Kraftmesseinrichtung mit Störgrößenkompensation, Deutsches Patent- und Markenamt/German Patent and Trade Mark Office, Berlin, Germany.

[17] Simscape Multibody Documentation, MathWorks, https://www.mathworks.com/help/physmod/sm/index.html.

[18] MILLER S., SOARES T., WEDDINGEN Y.V., WENDLANDT J., 2017, Modeling Flexible Bodies with Simscape Multibody Software. An Overview of Two Methods for Capturing the Effects of Small Elastic Deformations, Technical Paper, MathWorks.

[19] CRAIG R., BAMPTON M., 1968, Coupling of Substructures for Dynamic Analyses, AIAA Journal, American Institute of Aeronautics and Astronautics, 6/7, 1313-1319.

[20] Mechanical APDL 2019 R3, Theory Reference, ANSYS, https://www.ansys.com. 